\title{
The Customer Satisfaction Evaluation and Fuzzy Adaptive Control in The Supply Chain
}

\author{
Xiaobei Liang ${ }^{1}$ Bingyong Tang ${ }^{2}$ \\ ${ }^{1}$ School of Economics \& Management, Tongji University, Shanghai 200092, P. R China \\ ${ }^{2}$ Glorious Sun School of Business and Management, Dong Hua University, Shanghai 200051, P. R China
}

\begin{abstract}
The satisfaction of ultimate customer can measure with four gross criteria in the supply chain, and can subdivide into ten sub-criteria. Customer satisfaction mainly performs from customer, so there is certain preference as a weight to each criterion. The weight is difficult to focus on one point, but can establish the scope generally. Moreover, the decision maker has certain preference to each criterion according to the supply chain characteristics. In this paper, an overall evaluation of customer satisfaction in the supply chain on condition of the weight scope is researched by multiple criteria decision making theories and statistics. Moreover a fuzzy customer satisfaction adaptive control method based on the customer satisfaction model is presented in the supply chain.
\end{abstract}

Keywords: Supply chain, Customer satisfaction, Preference, Weight, Fuzzy adaptive control method

\section{Introduction}

As the market competition becomes fierce, most of corporations realize the importance of customers; and begin to pay more attention on their customer relationship management (CRM) project. Actually, CRM is a kind of marketing policy. It is to cultivate the personnel's, dealers' or customers' preference for the company to keep them, so that you can boost the company performance [1]. In other words, the operation of a company is based on customer loyalty. To reach this goal, the first thing you must do is to find and keep the right customers [2]. The 'right customers' refers to those who have the inclination to high satisfaction and loyalty, and can provide stable cash flow, as a result, to bring abundant profit to the company. These customers are very valuable for the company. So, scrutinizing customers and studying customer satisfaction and loyalty are very important for a company. However, satisfaction is a kind of psychological state, thus it is a subjective concept and is hard to measure. As a result, there are very few papers studying this customer satisfaction measurement problem. This paper gives a customer satisfaction measurement index system. In this system, a satisfaction coefficient is used to measure the customer satisfaction, which can be acquired by analyzing satisfaction related customer psychology factors and purchase behavior, and assessed by means of a fuzzy optimization.

The supply chain management is a new concept, which organizes from raw material, production to sale from a new aspect. The main idea of the supply chain management is to optimize the supply chain in an integrated approach, and then create the biggest value. The ultimate customer is market - oriented and profits source of the supply chain, he becomes the main drive of the performance [3]-[5]. Therefore, the research object of this paper, "customer" means ultimate consumer. In the supply chain, what customer purchases is an integration of products and service. Though it is integrated, a lot of products and service are placed to dividing appearances in the meantime. A customer always inclines toward an overall evaluation to product (include related service) or service while purchasing. The more satisfied a customer feels, the more high loyalty to that supply chains, and he is willing to introduce new customers further, create more profit opportunities for the supply chain. On the contrary, the customer dissatisfied will make the supply chain lose a profit opportunity. Today, a customer pays more attention to the increasing value of the product and the economy cost, even show the customer idea in each link of the supply chain. Therefore, the core to win customer is raising his satisfaction in the supply chain [6]. The raw material supplier, producer, wholesale dealer, dealer and ultimate customer, with the cooperation of the business colleagues, can realize the minimum cost, the best service, the biggest purchase value for customers. It is the core to operate the supply chain based on a customer.

Fuzzy set theory has grown to become a major scientific domain collectively referred to as fuzzy systems. It has been shown that there are a lot of applications in almost sub-areas of fuzzy systems. 
The stability results of a certain class of SISO discrete-time processes controlled by an adaptive fuzzy controller, by using Lyapunov stability theory were recently obtained for adaptive neural controllers [7]. The adaptive tracking control architecture is proposed for a class of continuous-time nonlinear dynamic systems, for which an explicit linear parameterization of the uncertainty in the dynamic is either unknown or impossible [8]. The new robust stability criteria to analyze the robust stability of the discrete Takagi-Sugeno (T-S) fuzzy dynamic model with time-varying consequent uncertainties are present [9]-[10]. Then this paper discusses the fuzzy adaptive control methods [11] for the customer satisfaction in the supply chain. The adaptive control algorithms can adjust the parameters and structures on-line in the control process and improve on-line adaptation.

\section{The weight criteria of customer satisfaction}

In Customer satisfaction can be measure by response speed, commitment, price and quality generally. The supply chain can make an effort from these four if wants to raise customer satisfaction then to raise a competition [12].

(1) Response speed

Response speed means the reaction ability of the supply chain when the environment changing. A customer is unique concern of right product, right service, and right quantity in right time from the supply chain, so the supply chain should be vivid to meet various requirements to satisfy the customer. (2) Commitment

That criterion reflects commitment ability of the supply chain. The commitment will make customer purchase without worry. The higher commitment level, the more customer satisfaction is. The commitment level of supply chain can be described by percentage of out of stock, rate of punctuality delivery and rate of complain.

(3) Price
Here use two kinds of price influencing the customer satisfaction. The smaller criterion, the more customer satisfaction is. One price comparing with average price reflects average price of each product comparing with target supply chain and rival supply chain. Another is average discount rate of each product, which reflects the direction of the marketing policy, and measure by average discount rate of each product.

\section{(4) Quality}

The quality includes the product quality and the service quality. The product quality can measure by the ratio of fix and return amount to total amount of purchase in a period of time. The smaller the criterion value, the higher customer satisfaction is. The service quality can measure by the time for solving customer complaint, the time means the period from the complaint cause to be solved successfully. The shorter of the time, the higher customer satisfaction is. To sum up, illustrate below in Figure 1.

\section{Evaluation model of customer satisfaction}

In the supply chain, it is difficult to make sure the weight of customer satisfaction. Suppose $w_{i} \in\left[c_{i}, d i\right]$, $0 \leqq c_{i} \leqq d_{i} \leqq 1\left(\mathrm{i}=1,2, \cdots, 10 ;\right.$ and $\left.\sum_{i=1}^{10} \quad w_{i}=1\right)$

[13] , $\mathrm{P}_{\mathrm{i}}$ is each criterion per customer satisfaction; $w_{i}$ is weight per criterion. Because every supply chain has its characteristic, suppose the decision maker's preference to $\mathrm{P}_{i}$ is $\mathrm{r}_{i}$. When the decision maker thinks that it is difficult to add some criterion, he should make a great effort to raise satisfaction; therefore, the preference will be less. The weight can be evaluated by scaling procedure, constructing twain judgment matrix, and eigenvector value method or approximation method [14].

Moreover, the customer has an expectation satisfaction value purchasing product, denoting $\mathrm{u}_{i}$ $(i=1,2, \cdots, 10) . \mathrm{u}_{i}$ can be got by questionnaire research,

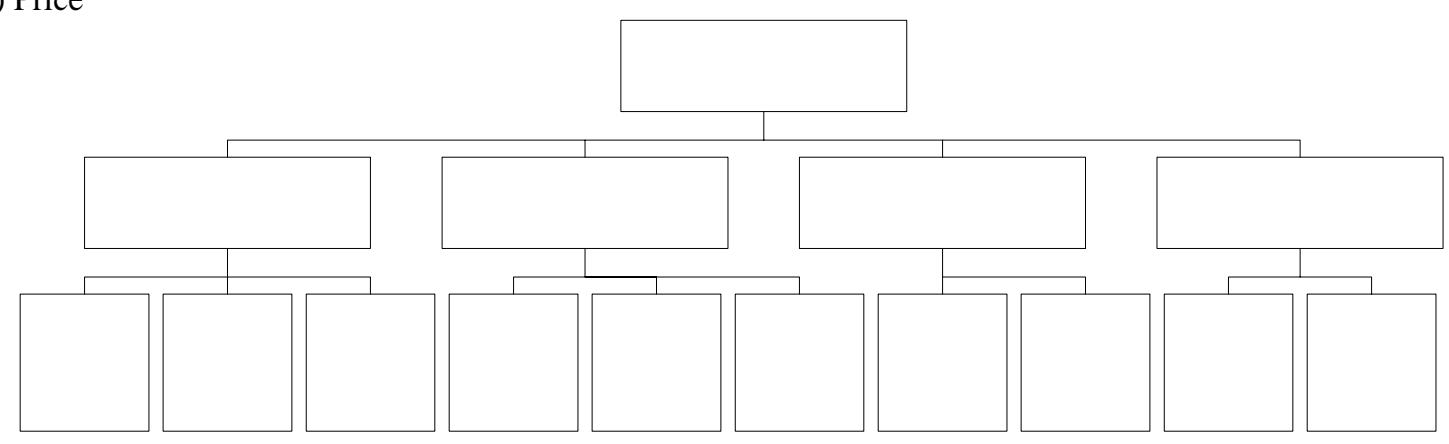

Figure 1: Customer satisfaction measure criterion structure. 


\begin{tabular}{|l|c|c|}
\hline \multicolumn{1}{|c|}{$\mathrm{p}_{i}$} & $\mathrm{u}_{\mathrm{i}} \leq \mathrm{v}_{\mathrm{i}}$ & $\mathrm{u}_{\mathrm{i}} \geqq \mathrm{v}_{\mathrm{i}}$ \\
\hline The higher $\mathrm{u}_{i}$, the higher customer satisfaction is & $\mathrm{u}_{\mathrm{i}} / \mathrm{v}_{i}$ & 1 \\
\hline The lower $\mathrm{u}_{i}$, the higher customer satisfaction is & 1 & $1-\left(\mathrm{u}_{i}-\mathrm{v}_{\mathrm{i}}\right) / \mathrm{v}_{i}$ \\
\hline
\end{tabular}

Table 1: Computational formula for measure criteria.

and statistical treatment. At the same time, the actual criterion value in the supply chain, denoting $\mathrm{v}_{i}$ $(i=1,2, \cdots, 10)$, can be got by its quantification formula. For benefit criterion, the higher criterion, the more customer satisfaction is. For loss criterion, the lower criterion, the more customer satisfaction is. Supposing $\mathrm{p}_{\mathrm{i}}$ is the accomplishing criterion of the $\mathrm{P}_{\mathrm{i}}$, it can use the computational formula as Table 1.

When appraising the customer satisfaction, $w_{i}$ is an object weight. Appraisal gets each criterion weight and the accomplishing criterion satisfaction in the supply chain. The total of the product of each criterion weight and accomplishing criterion are the integrated evaluation value for customer satisfaction. Owing to the subject weight, we hope get the least error causing by subject weight and the object weight, and can be solved by model (1). After getting the $w_{i}$, we can solve the overall evaluation of customer satisfaction in the supply chain according to $\sum_{i=1}^{10}$ $w_{i}{ }^{*} p_{i}$.

$$
\begin{aligned}
& \mathrm{G}=\min \left|\sum_{i=1}^{10}\left(W_{i}-r_{i}\right)^{*} p_{i}\right| \\
& \text { s.t. } \quad \sum_{i=1}^{10} W_{i}=1 \\
& c_{i} \leqq W_{i} \leqq d_{i} \quad i=1,2, \cdots, 10
\end{aligned}
$$

Because the target function exist an absolute value, we decompose the model to three parts for solving.

Supposing $\mathrm{F}=\sum_{i=1}^{10}$ (wi -ri)*pi then $\mathrm{G}=\min$ $\left(\mathrm{F}^{+},-\mathrm{F}^{-}, 0\right)$

Denotes $\mathrm{F}^{+}$is the minimum when $\mathrm{F}$ is positive number under the constraint condition; denote $\mathrm{F}^{-}$is the maximum when $\mathrm{F}$ is negative number under the constraint condition.

Decompose the model is as following:

$$
\begin{aligned}
& \sum_{i=1}^{10}\left(w_{i}-r_{i}\right)^{*} p_{i}=0 \\
& \sum_{i=1}^{10} \quad w_{i}=1, \quad c_{i} \leq w_{i} \leqq d_{i}, \quad i=1,2, \cdots, 10 \\
& \mathrm{~F}^{+}=\min \sum_{i=1}^{10} \quad\left(w_{i}-r_{i}\right)^{*} p_{i}
\end{aligned}
$$

$$
\begin{aligned}
& \text { s.t. } \sum_{i=1}^{10} \quad\left(W_{i}-r_{i}\right)^{*} p_{i} \geq 0 \\
& \sum_{i=1}^{10} \quad W_{i}=1, c_{i} \leq W_{i} \leq d_{i}, \quad i=1,2, \cdots, 10 \\
& \mathrm{~F}^{-}=\max \sum_{i=1}^{10}\left(W_{i}-r_{i}\right)^{*} p_{i} \\
& \text { s.t. } \sum_{i=1}^{10} \quad\left(W_{i}-r_{i}\right)^{*} p_{i} \leqq 0 \\
& \sum_{i=1}^{10} W_{i}=1 \quad c_{i} \leqq W_{i} \leqq d_{i} \quad i=1,2, \cdots, 10
\end{aligned}
$$

The solving process is as following:

A. If (2) exist solution, then the preference from the decision maker has no influence of integrated appraisal of customer satisfaction. Because $w_{i} \in\left[c_{i}\right.$, $\left.d_{i}\right], \sum_{1=1}^{0} w_{i}=1$, and from (2) $\sum_{i=1}^{10} w_{i}^{*} p_{i}=$ $\sum_{i=1}^{10}$ $\sum_{i=1}^{10} \quad c_{i}^{*} p_{i} \leqq \sum_{i=1}^{10} \quad r_{i}^{*} p_{i} \leqq \sum_{i=1}^{10} \quad d_{i}^{*} p_{i}$. If satisfying the inequality, then (2) exist solution, and integrated appraisal of customer satisfaction is $\sum_{i=1}^{10} \quad w_{i}^{*} p_{i}=\sum_{i=1}^{10} \quad r_{i}^{*} p_{i}$; Else do next.

B. Solve the line programming model (3) and(4) respectively. If (3) exists no solution, then $\mathrm{G}=\mathrm{F}^{+}$. If (4) exists no solution, then $G=-F^{-}$. If (3)(4) exist no solution, then $\mathrm{G}=\min \left(\mathrm{F}^{+},-\mathrm{F}^{-}\right)$. If $\mathrm{G}=$ $\mathrm{F}^{+}$, means decision maker overvalue the customer satisfaction, and $\sum_{i=1}^{10} w_{i}^{*} p_{i}=\sum_{i=1}^{10} r_{i}^{*} p_{i}+\mathrm{F}^{-}$. If $\mathrm{G}=-\mathrm{F}^{-}$, means decision maker underestimate the customer satisfaction, and $\sum_{i=1}^{10} w_{i}{ }^{*} p_{i}=$ $\sum_{i=1}^{10} r_{i}^{*} p_{i}+\mathrm{F}^{+}$.

Pay attention to when $G$ value is the same, perhaps there are some groups of weight, but it is no effect on the final solution. 


\begin{tabular}{|c|c|c|c|c|c|c|c|c|c|c|}
\hline$W_{i}$ & $\mathrm{C}_{1}$ & $\mathrm{C}_{2}$ & $\mathrm{C}_{3}$ & $\mathrm{C}_{4}$ & $\mathrm{C}_{5}$ & $\mathrm{C}_{6}$ & $\mathrm{C}_{7}$ & $\mathrm{C}_{8}$ & $\mathrm{C}_{9}$ & $\mathrm{C}_{10}$ \\
\hline $\mathrm{C}_{i}$ & 0.03 & 0.12 & 0.1 & 0.04 & 0.14 & 0.08 & 0.1 & 0.08 & 0.12 & 0.15 \\
\hline $\mathrm{d}_{i}$ & 0.05 & 0.18 & 0.15 & 0.07 & 0.22 & 0.15 & 0.15 & 0.12 & 0.2 & 0.28 \\
\hline
\end{tabular}

Table2: The weight scope of each criterion by customers

\begin{tabular}{|c|c|c|c|c|c|c|c|c|c|}
\hline $\mathrm{p}_{1}$ & $\mathrm{p}_{2}$ & $\mathrm{p}_{3}$ & $\mathrm{p}_{4}$ & $\mathrm{p}_{5}$ & $\mathrm{p}_{6}$ & $\mathrm{p}_{7}$ & $\mathrm{p}_{8}$ & $\mathrm{p}_{9}$ & $\mathrm{p}_{10}$ \\
\hline 0.815 & 0.821 & 0.863 & 0.911 & 0.897 & 0.886 & 0.923 & 0.954 & 0.936 & 0.911 \\
\hline
\end{tabular}

Table3: Accomplishing customer satisfactions in the supply chain

\section{Application of evaluation model}

According to research and descriptive statistical analysis, we get each criterion weight one of $w_{i}$. (see Table 2).

The decision maker uses 1-9 scaling procedure, construct twain judgment matrix $\mathrm{P}$ of criteria weight, as [15]. Solve the subject weight $r_{i}$ from decision maker by geometric mean approximation method.

The decision maker computes accomplishing customer satisfaction $\left(\mathrm{p}_{\mathrm{i}}\right)$ according to Table 1 , the solution is as following (Table 3).

According to $\sum_{i=1}^{10} \quad c_{i}^{*} p_{i}=0.859, \quad \sum_{i=1}^{10}$ $d_{i} * p_{i}=1.407, \sum_{i=1}^{10} r_{i}^{*} p_{i}=0.8924$, then

$\sum_{i=1}^{10} \quad c_{i}^{*} p_{i} \leqq \sum_{i=1}^{10} \quad r_{i}^{*} p_{i} \leqq \sum_{i=1}^{10} \quad d_{i}^{*} p_{i}$

Therefore, the preference of decision maker has no effect on the integrated appraisal of customer satisfaction, and the customer satisfaction is $89.24 \%$.

\section{A customer loyalty fuzzy adaptive control method}

\subsection{Fuzzy parameter estimation and forecasting algorithms}

For some general consideration, we take the timevarying fuzzy linear system model:

$$
\underset{\sim}{y_{j}}(k)=\sum_{s=1}^{n} \alpha_{s}^{j}(k) \underset{\sim}{x_{s}}(0)+\sum_{l=1}^{r} \sum_{j=1}^{\alpha} \beta_{l p}^{j}(k) \underset{\sim}{u_{l}}(k-p) \underset{\sim}{\sim} \underset{\sim}{\sim}(k)
$$

If let:

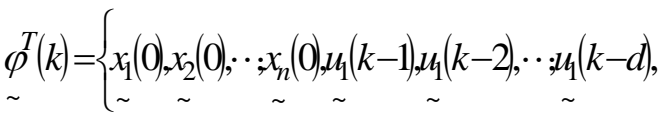

$$
\begin{aligned}
& \left.\underset{\sim}{u_{2}}(k-1) ; \cdots ; u_{\sim}(k-d), \cdots ; \underset{\sim}{u_{r}}(k-1), \cdots ; u_{r}(k-2)\right\} \\
& \theta_{j}^{T}(k)=\left\{\alpha_{1}^{j}(k), \alpha_{2}^{j}(k), \cdots ; \alpha_{n}^{j}(k), \beta_{11}^{j}(k), \beta_{12}^{j}(k), \cdots \beta_{1 d}^{j}(k),\right. \\
& \left.\beta_{21}^{j}(k), \cdots ; \beta_{2 d}^{j}(k), \cdots ; \beta_{r 1}^{j}(k), \cdots ; \beta_{r d}^{j}(k)\right\} \\
& \underset{\sim}{\varphi}(k)=[\varphi(k), \underset{-}{\varphi}(k), \bar{\varphi}(k)]_{L R}
\end{aligned}
$$

Then. (5) can be transformed into:

$$
\underset{\sim}{y_{j}}(k)=\theta_{l}^{T}(k) \underset{\sim}{\varphi}(k)+\underset{\sim}{e_{j}}(k) \underset{j=1,2, \cdots, m}{ }
$$

Thus, the parameter gradient recursive estimation ormula obtained from the known data of fuzzy input and output can be presented as follows:

$$
\begin{gathered}
\hat{\theta}_{j}(k)=\hat{\theta}_{j}(k-1)+\frac{\varphi(k)}{\|\varphi(k)\|^{2}}\left\{\left(y_{j}(k)-\hat{\theta}_{j}^{T}(k-1) \varphi(k)\right\}\right. \\
i=1,2, \cdots, m
\end{gathered}
$$

where $\hat{\theta}_{j}(k)$ represents the estimate value of $\theta_{j}(k), y_{j}(k)$ is the main value of the L-R fuzzy number $\underset{\sim j}{y}(k)$.

The "past" and "present" estimate value series $\left\{\hat{\theta}_{j}(1), \hat{\theta}_{j}(2), \cdots, \hat{\theta}_{j}(N)\right\}(\mathrm{N}$ is the present time), are obtained by (7), and are analyzed to find their 
regulation[16]. With the proper mathematical method [17-18], a series of forecasting value $\hat{\theta}_{j}^{*}(N+1), \cdots, \hat{\theta}_{j}^{*}(N+h)$ can be further obtained. Here, $h$ is a forecasting step length[19].

\subsection{The adaptive fuzzy control algorithm}

Then, a fuzzy customer satisfaction adaptive control method is as follows [16]:

$$
\underset{\sim}{y}(k-1)=b_{0}^{\mathrm{T}} \mu(k)+\varphi_{\sim}^{\mathrm{T}}(k+1) \underset{\sim}{\theta}(k+1),
$$

where $y(k)$ is one-dimensional fuzzy output (the pension sale) and $\mu(k)$ is a $r$-dimensional fuzzy input $(\quad(r \geq 1)$ example, relationship permanence, consumption amount, emotional factors and so on. The vector $b_{0}$ is the known non-zero constant. The fuzzy vector $\varphi(k+1)$ consists of a fuzzy input and fuzzy output at one time of the system. The vector $\theta(k+1)$ is composed of fuzzy parameters. From the above fuzzy parameter estimate algorithm, we know that the recursive estimate formula [18] for fuzzy $\theta(k)$ in (8) is as follows:

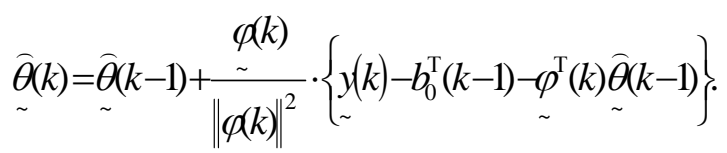

In calculation, the estimation of the vector $\theta(k)$ can be separated into the estimations of its branch $\underset{\sim i}{\theta}(k)$. Further, the fuzzy parameter estimate value $\hat{\theta}^{*}(k+1)$ can be obtained by the fuzzy parameter forecasting algorithm [18] at the $k+1$ time. The algorithm [20] for (9) is:

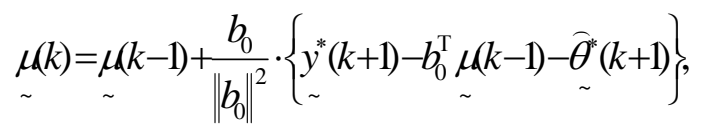

where $y^{*}(k+1)$ is anticipated fuzzy output at the $k+1$ time.

\subsection{The application in the supply chain}

The proposed method has been applied to the adaptive control in the supply chain. The mathematical model is as follows:

$$
\underset{\sim}{y}(k)=b_{0}^{\mathrm{T}} \underset{\sim}{\mu}(k)+\underset{\sim}{\varphi^{\mathrm{T}}}(k) \underset{\sim}{\theta}(k),
$$

where $y(k)$ is one-dimensional fuzzy output and $\mu(k)$ is a 3-dimensional fuzzy input, $b_{0}$ is a definite non-zero constant estimate vector:

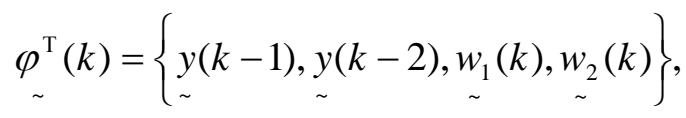

$$
\begin{aligned}
& \theta_{\sim}^{\mathrm{T}}(k)=\left\{\underset{\sim}{a_{1}}(k), \underset{\sim}{a_{2}}(k), \underset{\sim}{a_{3}}(k) \cdot \underset{\sim}{a_{4}}(k)\right\},
\end{aligned}
$$

Here $w_{1}(k)$ and $w_{2}(k)$ are infective factors. According to the historical data, $\theta(k)$ can be estimated by the fuzzy parameter estimation (9). Further, in the following adaptive control algorithm:

$$
\underset{\sim}{\mu}(k)=\underset{\sim}{\mu}(k-1)+\frac{b_{0}}{\left\|b_{0}\right\|^{2}} \cdot\left\{y_{\sim}^{*}(k)-b_{\sim}^{\mathrm{T}} \underset{\sim}{\mu(k-1)}-\varphi_{\sim}^{*}(k-1)\right\},
$$

here $y^{*}(k)$ is the anticipated output at $k$ time (fuzzy number).

For example, if $y^{*}(k)=(500,0.5,0.4)(\mathrm{k}=21)$, then by (16), we have

$\mathrm{u}(21)=\{(0.92,0.52,0.32),(0.81,0.28,0.37)$, $(0.94,0.42,0.29)\}$.

Similarly, we can obtain u (22), u (23), ..., and so on.

\section{Conclusions}

In this paper, a method of an overall evaluation of customer satisfaction in the supply chain is given. The criterion weight is difficult to focus on one point, but the scope for premise can be made sure. Each criterion value can be solved by formula under the concrete situation. The main purpose of this paper is giving a method and an idea to an integrated 
appraisal of customer satisfaction in the supply chain, bringing guidance for industry. Each supply chain should accord to own product, the chain structure and other characteristics for appropriate adjustment when adopting the method. Moreover, for various supply chain projects, the integrated appraisal of customer satisfaction under various situations can be gotten, and then a comparison can be made. The results from this paper can be in general applied to a class of timevarying systems in which conventional control techniques have been used for many years.

\section{Acknowledgement}

This work is supported by Nature Science Foundation of Shanghai (Grant No. 05ZR14091).

\section{References}

[1] F. Newell, Customer Relationship Management in the New Era of Internet Marketing, Huaxia Publishing House, 2001.

[2] D. J. Hawkins, et. al. Consumer Behavior, The McGraw-Hill Company, 2000.

[3] Y. Wang, The practicable methods for setting up mold and data excavation in the supply chain management, Qinghua University press, Beijing, 2001.

[4] S. Christoph, Z. Kirstin, Hierarchical coordination mechanisms within the supply chain. European Journal of Operational Research, 153 (3): 687-699, 2004.

[5] V. Gaur, A. Giloni, S. Seshadri, Information Sharing in a supply chain under ARMA Demand. Management Science, 6: 961-970, 2005.

[6] Y. Wang, The competitive in supply chaincustomer satisfaction. Industry engineering and management, 2: 33-35, 1999.

[7] J. Renders, M. Saerens and H. Bersini, Fuzzy adaptive control of a certain class of SISO discrete-time processes. Fuzzy Sets and Systems 85 (1): 49-61, 1997.

[8] C. Shao, Q. Li and T. Chai, Fuzzy adaptive control for a class of nonlinear systems. Fuzzy Sets and Systems 101(1): 31-39, 1999.

[9] J. Chou and S. Chen, Stability analysis of the discrete Takagi-Sugeno fuzzy model with timevarying consequent uncertainties. Fuzzy Sets and Systems 118: 271-279, 2001.

[10] T. Takagi, M. Sugeno, Fuzzy identification of systems and its application to modeling and control. IEEE Trans. Syst, Man and Cybern, 15 (1): 116-132, 1985.
[11] B. Tang, L. Xu, W. Wang, An adaptive control method for time-varying systems. European Journal of Operational Research, 124: 342-352, 2000.

[12] J. Huo, M. Sui, and Z. Liu, Setting up an evaluation system of general performance appraisal for the integration supply chain. Tongji University press, 30(4): 495-499, 2002.

[13] F. Gao, Multi criteria decision making of preference to cases under incompletion information. System engineering theory and practice, (4): 94-97, 2000.

[14] <Operational research> teaching material writegroup <Operational Research> Tutorial. Qinghua University press, 6: 463-465, 2001.

[15] X. Liang, B. Tang, Y. Zeng, An Overall Evaluation of Customer Satisfaction in the Supply Chain. Proceedings of the Fifth Wuhan International Conference on E-Business, pp. 27-32, 2007.

[16] D. Dubois, H. Prade, Fuzzy Sets and SystemsTheory and Applications, Acad Press, New York, 1980.

[17] X. Liang, B. Tang, Y. Xue, Z. Zhu, Fuzzy adaptive control based on L-R fuzzy number and application in the pension systems. Applied Computational Intelligence-Proceedings of the 6th International FLINS Conference, pp. 334337, 2004.

[18] Z. Han, The identification of time-varying parameter in dynamic system. Acta automatica sinica, 10(4): 381-387, 1984.

[19] B. Tang, Identification of fuzzy models and its application, China Environmental Science Press, Beijing, 1994.

[20] Z. Han, Adaptive control algorithms versus parameter estimations. Control Theory and Applications, 9(6): 374-379, 1992. 